\title{
The Mediating Effect of Impulsivity on Resilience and Depressive Symptoms In Korean Conscripts
}

\author{
Dongyun Lee ${ }^{1,2} \bowtie$, So-Jin Lee ${ }^{2,3}$, Chul-Soo Park ${ }^{2,3}$, Bong-Jo Kim ${ }^{2,3}$, \\ Cheol-Soon Lee ${ }^{1,2}$, Boseok Cha ${ }^{2,3}$, Ji-Yeong Seo', and Jae-Won Choi ${ }^{3}$ \\ 1'Department of Psychiatry, Gyeongsang National University Changwon Hospital, Changwon, Republic of Korea \\ 2Department of Psychiatry, Gyeongsang National University College of Medicine, Jinju, Republic of Korea \\ ${ }^{3}$ Department of Psychiatry, Gyeongsang National University Hospital, Jinju, Republic of Korea
}

Objective Resilience and impulsivity have opposite effects on depression in stressful situations. This study aimed to investigate the association among resilience, impulsivity, and depression in young males.

Methods The participants consisted of 429 conscripts who underwent military training over 5 weeks. The surveys included the Connors-Davidson Resilience Scale-Korean version, the Barratt Impulsiveness Scale-11-Revised, and the Center for Epidemiological Studies-Depression Scale. The surveys were administered both before and after training.

Results When simultaneously considering impulsivity and resilience, resilience was not associated with depression. Impulsivity had a complete negative mediating effect on resilience and depressive symptoms. Impulsivity is a significant negative mediating factor for the protective effect of resilience on depression.

Conclusion This study recommends considering impulsivity when evaluating the protective role of resilience against depression.

Psychiatry Investig 2019;16(10):773-776

Key Words Impulsivity, Resilience, Depression, Mediating effect.

\section{INTRODUCTION}

Military service in Korea is compulsory, and various psychiatric problems related to military service have arisen in countries worldwide. ${ }^{1,2}$ During mandatory military service, negative aspects of military enlistment act as stressors, which can cause depression in young Korean males. ${ }^{2,3}$

Stress-related symptoms that differ in severity may occur among individuals exposed to similar levels of stress, and the level of symptom severity is related to individual characteristics and the level of resilience, which has been defined as the ability to adapt or overcome adversity or stress and to grow psychologically. Therefore, studies on resilience in members of the military have focused on the prevention and treatment

Received: January 10, 2019 Revised: February 26, 2019

Accepted: April 2, 2019

$\triangle$ Correspondence: Dongyun Lee, $\mathrm{MD}, \mathrm{PhD}$

Department of Psychiatry, Gyeongsang National University Changwon Hospital, 11 Samjeongja-ro, Seongsan-gu, Changwon 51472, Republic of Korea

Tel: +82-55-214-3801, Fax: +82-55-214-3254, E-mail: yuny0829@gmail.com

(c) This is an Open Access article distributed under the terms of the Creative Commons Attribution Non-Commercial License (https://creativecommons.org/licenses/by$\mathrm{nc} / 4.0$ ) which permits unrestricted non-commercial use, distribution, and reproduction in any medium, provided the original work is properly cited. of depression. $^{5}$

Impulsivity is associated with stress vulnerability, which increases the risk of psychiatric problems. ${ }^{6}$ Because individuals with high impulsivity face stressful situations through error-prone information processing, they tend to exhibit more problematic behaviors. ${ }^{7}$ In particular, impulsive young males in stressful situations have a greater risk for depressive symptoms. $^{8}$

This impulsivity seems to be associated with resilience and depressive symptoms. However, previous studies did not suggest a definite association among these three variables in subjects without psychiatric disease. Therefore, our study evaluated the association among impulsivity, resilience and depressive symptoms in young males who undergo stressful military enlistments.

\section{METHODS}

All participants were confirmed to be free of marked psychiatric and physical diseases by the national draft examination. A total of 459 males were included, as only young males above 18 years of age have military service obligations. They 
all performed basic military training for 5 weeks. The survey was performed to evaluate the mental health of Korean conscripts during basic military training. The survey was conducted twice, before and after basic military training, by selfquestionnaire. The questionnaires included sociodemographic characteristics, such as age, level of education (years), and exercise duration. Impulsivity and resilience, which were evaluated by the Barratt Impulsiveness Scale-11-Revised (BIS-11-R) and the Connors-Davidson Resilience Scale-Korean version (CD-RISC), were surveyed before basic military training. The Center for Epidemiological Studies-Depression Scale (CESD) was used to evaluate depressive symptoms after training. The subjects agreed to participate in this study after they were given a full explanation of the study from a board-licensed psychiatrist, and all participants provided informed consent. This study was approved by the Clinical Medical Research Ethics Committee of the Korean Armed Forces Medical Command (IRB number: ROK-MND-2015-KMMRP-02).

The BIS-11-R consists of 30 items, and each item is answered according to a 4 point-Likert scale. This scale has been used to evaluate the trait of impulsivity. The BIS-11-R evaluates three subdomains: attention, motor, and non-planning. A higher score indicates a higher degree of impulsivity. The validity and reliability of the Korean version of the BIS-11-R were determined using a general population in Korea (Cronbach's $\alpha=0.783){ }^{9}$

The CD-RISC consists of 25 items and was used to determine psychological resilience. Each item is answered according to a 5 point-Likert scale. A higher summed score indicates a higher degree of resilience. The validity and reliability of the CD-RISC-Korean version were determined using a general population and psychiatric patients in previous studies (Cronbach's $\alpha=0.92,0.93) .{ }^{10,11}$

The CES-D consists of 20 items, and each item was answered according to a 4 point-Likert scale. The cut-off point for screening of depression is greater than 16. This point was used to separate the depression and control groups in this study. The validity and reliability of the Korean version of the CES-D were determined using clinical patients and normal subjects (Cronbach's $\alpha=0.893$ ). ${ }^{12}$

An independent t-test was performed to compare sociodemographic characteristics and the mean BIS-11-R and CDRISC scores between the depression group (CES-D $\geq 16)$ and the control group $(\mathrm{CES}-\mathrm{D}<16)$. The correlations among the mean BIS-11-R, CD-RISC, and CES-D scores were evaluated by Pearson's correlation. Binary logistic regression analyses were performed to evaluate risk factors of depression after training. The independent variables were age, level of education, exercise duration, BIS-11-R scores (total, attention, motor, and non-planning; these analyses were performed twice separately for the total and subtypes because of multicollinearity), and CD-RISC scores. A path analysis was performed to evaluate the mediating effect of impulsivity on resilience and depressive symptoms after training. The bootstrapping for indirect effect was 200 [confidence interval (CI): 95\%] in the pathway analysis. All statistical analyses were performed using SPSS version 21.0 (IBM Corp., Armonk, NY, USA) and AMOS 18.0 (SPSS Inc., Chicago, IL, USA). A two-tailed p-value $<0.05$ was considered statistically significant.

\section{RESULTS}

The mean $( \pm S D)$ values for age, level of education, and exercise duration of the depression group $(n=60)$ were 20.6 $( \pm 1.8)$ years, $12.7( \pm 1.1)$ years, and $89.0( \pm 164.6)$ minutes/ week, respectively. The mean $( \pm S D)$ values for age, level of education, and exercise duration of the control group $(n=369)$ were $20.5( \pm 1.5)$ years, $12.8( \pm 1.2)$ years, and $138.9( \pm 211.4)$ minutes/week, respectively. The mean exercise duration was significantly different between the two groups ( $\mathrm{p}=0.040)$; the other variables showed no significant differences.

Significant differences were observed between the two groups for the mean total, attention, motor and non-planning BIS-11-R scores and the CD-RISC scores. The mean scores for the depression and control groups, were $69.4( \pm 11.1)$ and 61.2 ( \pm 9.0$), \mathrm{p}<0.001 ; 23.2( \pm 4.9)$ and $20.4( \pm 3.9), \mathrm{p}<0.001$; $28.0( \pm 4.5)$ and $25.3( \pm 4.2), \mathrm{p}<0.001,18.2( \pm 3.8)$ and 15.5 $( \pm 3.0), \mathrm{p}<0.001$; and $59.8( \pm 18.2)$ and $68.2( \pm 15.6), \mathrm{p}<0.001$, respectively.

The CES-D score after training was significantly correlated with the total BIS-11-R score $(r=0.289, \mathrm{p}<0.001)$, the scores for the attention $(r=0.254, p<0.001)$, motor $(r=0.248, p<0.001)$ and non-planning $(\mathrm{r}=0.219, \mathrm{p}<0.001)$ subdomains and the CD-RISC $(r=0.201, p<0.001)$ score. The CD-RISC score was significantly correlated with the total BIS-11-R ( $r=-0.396$, $\mathrm{p}<0.001)$ and attention $(\mathrm{r}=-0.333, \mathrm{p}<0.001)$, motor $(\mathrm{r}=-0.250$, $\mathrm{p}<0.001)$ and non-planning $(\mathrm{r}=-0.397, \mathrm{p}<0.001)$ subdomain scores.

The odds ratios (OR) for depression after training according to the BIS-11- $\mathrm{R}$ total score was significant $(\mathrm{B}=0.080$, $\mathrm{SE}=0.017, \mathrm{OR}=1.083, \mathrm{CI}=1.047-1.120, \mathrm{p}<0.001)$. The $\mathrm{OR}$ for depression after training according to the CD-RISC score was not significant $(\mathrm{B}=-0.012, \mathrm{SE}=0.010, \mathrm{OR}=0.988, \mathrm{CI}=0.970$ $-1.006, p=0.195)$. The ORs for age $(p=0.623)$, level of education $(\mathrm{p}=0.588)$, and exercise duration $(\mathrm{p}=0.646)$ were not significant. In an analysis including the BIS-11-R subdomains, the attention subdomain was a significant risk factor $(\mathrm{B}=0.171, \mathrm{SE}=0.059, \mathrm{OR}=1.187, \mathrm{CI}=1.058-1.137, \mathrm{p}=0.004)$. The ORs for the CD-RISC $(p=0.247)$, motor subdomain $(p=0.401)$, non-planning subdomain $(\mathrm{p}=0.187)$, age $(\mathrm{p}=0.570)$, level of 
education ( $\mathrm{p}=0.542)$, and exercise duration $(\mathrm{p}=0.828)$ were not significant. In an additional analysis that only included age, level of education, exercise duration, and CD-RISC as independent variables, the $\mathrm{CD}$-RISC score a was significant protective factor for depression $(\mathrm{B}=-0.029, \mathrm{SE}=0.009, \mathrm{OR}=0.972$, $\mathrm{CI}=0.955-0.989, \mathrm{p}=0.001$ ).

Figure 1 shows the relationship among impulsivity, resilience, and depressive symptoms after training determined by path analysis. Impulsivity had a completely negative mediating effect on resilience and depressive symptoms; the indirect effect was -0.098 ( $\mathrm{p}=0.005)$, and the total effect was -0.201 $(\mathrm{p}=0.009)$. The direct effect on resilience and depressive symptoms was not significant.

\section{DISCUSSION}

We investigated the association between impulsivity and resilience as factors that affect depression after military training in young males. High resilience significantly decreased the risk for depression when only sociodemographic variables were considered. However, when impulsivity was also considered, resilience was not significantly associated with depression. Especially in the results of the path analysis, impulsivity completely mediated the negative association between resilience and depression, and the direct effect was not significant for the relationship between resilience and depressive symptoms. These results indicate that impulsivity meaningfully negatively affects the protective role of resilience against depression. Personality traits related to self-regulation, such as neuroticism, might be associated with this mediation. ${ }^{13-15}$

Neuroticism represents individual differences in adjustment and emotional stability. ${ }^{16}$ Individuals with increased neuroticism make impulsive judgments by failing to self-regulate rather than by determining proper coping strategies. ${ }^{17}$ Similarly, individuals with increased impulsivity have a tendency to experience strong impulses under conditions of negative affect, and they are likely to engage in impulsive behaviors to alleviate negative emotions despite the long-term harmful consequences. Moreover, increased impulsivity has been positively related to neuroticism, ${ }^{15}$ and resilience has shown

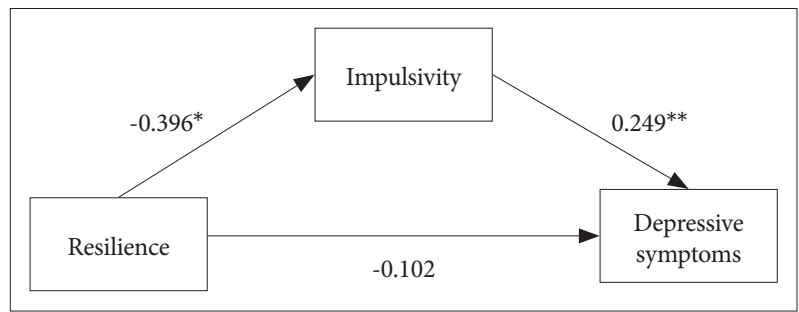

Figure 1. Path analysis of resilience, impulsivity and depressive symptoms. ${ }^{*} p<0.05,{ }^{* *} p<0.01$. a strong negative relationship with neuroticism. ${ }^{13,18}$ Neurotic individuals use negative coping strategies in stressful situations. ${ }^{16}$ Thus, these people are considered less resilient and are vulnerable to depression. In this context, neuroticism can be a factor that accounts for the complete mediating effect of impulsivity on resilience and depression, which is the main focus of this study.

This study has several limitations. First, it is difficult to generalize the results of this study to the general population because all subjects were men in their early twenties. Second, the participants of this study were all subjects who must complete training as a part of compulsory military service. Therefore, their survey responses might not reflect their true feelings. However, as described in the methods section, the researcher emphasized that not participating in the study would not affect their training.

In conclusion, impulsivity has a complete negative mediating effects on resilience and depression. Recently, the importance of resilience has been emphasized not only in situations of severe trauma, such as war, abuse, and violence, but also in overcoming workplace adversity experienced in daily life. ${ }^{19}$ Therefore, this study suggests considering impulsivity when evaluating the protective role of resilience against depression.

\section{Acknowledgments}

This work was supported by the Korean Military Medical Research Project of the ROK Ministry of National Defense (ROK-MND-2015-KMMRP-02).

\section{Conflicts of Interest}

The authors have no potential conflicts of interest to disclose.

\section{Author Contributions}

Conceptualization: Dongyun Lee, So-Jin Lee, Chul-Soo Park. Data curation: Dongyun Lee, Cheol-Soon Lee. Formal analysis: Dongyun Lee. Funding acquisition: Dongyun Lee. Investigation: Ji-Yeong Seo, Jae-Won Choi. Methodology: Dongyun Lee, Cheol-Soon Lee. Project administration: Dongyun Lee, Cheol-Soon Lee. Resources: Dongyun Lee. Software: Dongyun Lee. Supervision: So-Jin Lee, Chul-Soo Park, Bong-Jo Kim, Cheol-Soon Lee, Boseok Cha, Ji-Yeong Seo, Jae-Won Choi. Validation: So-Jin Lee, Boseok Cha. Visualization: Dongyun Lee. Writing-original draft: Dongyun Lee. Writing—review \& editing: Dongyun Lee.

\section{ORCID iD}

Dongyun Lee https://orcid.org/0000-0002-3977-3663

\section{REFERENCES}

1. Kim H, Kim SA, Kong S. Resilience mediates impact of some childhood maltreatment on post-traumatic stress symptoms in conscripted marines in the Republic of Korea. Res Nurs Health 2016;40:51-62.

2. Rodriguez JR, Quinones-Maldonado R, Alvarado-Pomales A. Military suicide: factors that need to be taken into consideration to understand the phenomena. Bol Asoc Med P R 2009;101:33-41.

3. Choi K, Im H, Kim J, Choi KH, Jon DI, Hong H, et al. Relationship of early-life stress and resilience to military adjustment in a young adulthood population. Soc Psychiatry Psychiatr Epidemiol 2013;48:1767-1776. 
4. Masten AS. Resilience in Individual Development: Successful Adaptation Despite Risk and Adversity. In: Wang MC, Gordon, EW, Editors. Educational Resilience in Inner-City America: Challenges and Prospects. Hillsdale, NJ: Lawrence Erlbaum Associates Inc, 1994, p. 3-25.

5. Institute of Medicine (IOM). A Vision and Goals for Workforce Readiness and Resilience. In: Medicine IO, Editor. A Ready and Resilient Workforce for the Department of Homeland Security: Protecting America's Front Line. Washington, DC: The National Academies Press, 2013, p. 59-87.

6. Lee DY, Lee CS, Park CS, Kim BJ, Cha BS, Lee S, et al. Relationship among adult attention deficit hyperactivity disorder, depression and suicide idea in Korean soldiers. J Korean Soc Biol Ther Psychiatry 2012;18:209-215.

7. Dickman SJ. Functional and dysfunctional impulsivity: personality and cognitive correlates. J Pers Soc Psychol 1990;58:95-102.

8. Ahn IY, Lee D, Park CS, Kim BJ, Lee CS, Cha B, et al. The effects of impulsivity on suicide ideation in conscripts - the mediating effect of depressive symptoms and stress-related symptoms. J Korean Soc Biol Ther Psychiatry 2016;22:108-115.

9. Lee SR, Lee WH, Park JS, Kim SM, Kim JW, Shim JH. The study on reliability and validity of Korean version of the Barratt impulsiveness scale-11-revised in nonclinical adult subjects. J Korean Neuropsychiatr Assoc 2012;51:378-386.

10. Baek HS, Lee KU, Joo EJ, Lee MY, Choi KS. Reliability and validity of the Korean version of the connor-davidson resilience scale. Psychiatry Investig 2010;7:109-115.
11. Jung YE, Min JA, Shin AY, Han SY, Lee KU, Kim TS, et al. The Korean version of the Connor-Davidson resilience scale: an extended validation. Stress Health 2012;28:319-326.

12. Cho MJ, Kim KH. Use of the center for epidemiologic studies depression (CES-D) scale in Korea. J Nerv Ment Dis 1998;186:304-310.

13. Campbell-Sills L, Cohan SL, Stein MB. Relationship of resilience to personality, coping, and psychiatric symptoms in young adults. Behav Res Ther 2006;44:585-599.

14. Friborg O, Barlaug D, Martinussen M, Rosenvinge JH, Hjemdal O. Resilience in relation to personality and intelligence. Int J Methods Psychiatr Res 2005;14:29-42.

15. Whiteside SP, Lynam DR. The five factor model and impulsivity: using a structural model of personality to understand impulsivity. Pers Individ Dif 2001;30:669-689.

16. Costa PT, McCrae RR. The Revised Neo Personality Inventory (NEOPI-R). In: Boyle GJ, Matthews G, Saklofske DH, Editors. The SAGE Handbook of Personality Theory and Assessment. Thousand Oaks, CA: Sage Publications Inc, 2008, p.179-198

17. Bienvenu OJ, Stein MB. Personality and anxiety disorders: a review. J Pers Disord 2003;17:139-151.

18. Furnham A, Crump J, Whelan J. Validating the NEO personality inventory using assessors ratings. Pers Individ Dif 1997;22:669-675.

19. Jackson D, Firtko A, Edenborough M. Personal resilience as a strategy for surviving and thriving in the face of workplace adversity: a literature review. J Adv Nurs 2007;60:1-9. 